\title{
Awareness, anxiety, and depression in healthcare professionals, medical students, and general population of Pakistan during COVID-19 Pandemic: A cross sectional online survey
}

\author{
Sardar Muhammad Alfareed Zafar ${ }^{1,2}$, Muhammad Junaid Tahir*1,2 (1D, Muna Malik ${ }^{1,2,3}$, Muhammad Irfan Malik ${ }^{1,2,4,5}$, \\ Fahd Kamal Akhtar ${ }^{1,2,6,7}$, Rubi Ghazala ${ }^{1,2}$
}

Received: 18 Jun $2020 \quad$ Published: 6 Oct 2020

\begin{abstract}
Background: COVID-19 (coronavirus disease 2019) pandemic has seriously affected the entire world. This study was aimed to assess prevalence and influencing factors of anxiety and depression during the pandemic in our Pakistani population, including healthcare professionals, undergraduate medical students, and general public.

Methods: An online cross sectional survey was conducted; with a questionnaire having demographic profile, COVID-19-related knowledge/awareness, self-rating anxiety scale (SAS), and self-rating depression scale (SDS). A total of 1014 people responded to the survey. Chi square test was used to compare different groups, and logistic regression models were used to explore influencing factors for anxiety and depression symptoms.

Results: Of the 1014 respondents, $92.6 \%$ were aware of COVID-19, and the prevalence rate of anxiety and depression symptoms was $4.6 \%$ and $14.3 \%$, respectively. Healthcare professionals had more awareness about COVID-19 as compared to medical students and general public $(p<0.001)$. Logistic regression models showed females, and people who were not aware of COVID-19 ( $\leq 6$ points score) were more likely to have both anxiety and depression symptoms $(\mathrm{p}<0.05)$, the general public had more anxiety than healthcare professionals $(\mathrm{p}<0.05)$, while undergraduate medical students and young people had only depression $(\mathrm{p}<0.05)$.

Conclusion: Although major mental health burden is not present in Pakistan, but there is a dire need to pay more attention to vulnerable groups like young people, undergraduate medical students, and women. Psychological interventions are required to reduce the psychological impact of COVID-19 pandemic.
\end{abstract}

Keywords: Corona Virus Disease 2019 (COVID-19), Awareness, Anxiety, Depression, Mental health

Conflicts of Interest: None declared

Funding: None

*This work has been published underCC BY-NC-SA 1.0 license.

Copyright $\odot$ Iran University of Medical Sciences

Cite this article as: Muhammad Alfareed Zafar S, Junaid Tahir M, Malik M, Irfan Malik M, Kamal Akhtar F, Ghazala R. Awareness, anxiety, and depression in healthcare professionals, medical students, and general population of Pakistan during COVID-19 Pandemic: A cross sectional online survey.Med J Islam Repub Iran. 2020(6 Oct);34:131. https://doi.org/10.47176/mjiri.34.131

Introduction

Since December 2019, COVID-19 (coronavirus disease

Corresponding author: Dr Muhammad Junaid Tahir, junaid262626@gmail.com

1. Lahore General Hospital, Lahore, Pakistan

2. Ameer-ud-Din Medical College, Lahore, Punjab, Pakistan

3. Medical Microbiology \& Infectious Diseases Society of Pakistan

Pakistan Chest Society

5. European Respiratory Society

6. Pakistan Oculoplastic Association

7. Ophthalmological Society of Pakistan
2019), a cluster of acute respiratory illness with unknown

$\uparrow$ What is "already known" in this topic:

Due to COVID-19 pandemic, most of the people are experiencing anxiety and depression like symptoms. Lockdown and high transmission potential of COVID-19 are 2factors causing mental distress in people. Thus, this study was aimed to find the risk and influencing factors of developing mental health problems in Pakistani population.

\section{$\rightarrow$ What this article adds:}

The result of this study showed that most of the people are well aware of COVID-19, and anxiety and depression symptoms are significantly associated with females and people who are not well aware. Mental health of undergraduate medical students and young people are at more risk of developing psychological symptoms. 
etiology, occurred in Wuhan Hubei province China (13 ). The infectious disease agent was named as SARS-CoV2 (severe acute respiratory syndrome-coronavirus-2) by the International Committee on Taxonomy of Viruses because of its resemblance to SARS coronavirus(4). The characteristics of COVID-19 resemble SARS (severe acute respiratory syndrome) and MERS (Middle East respiratory syndrome) outbreaks that occurred in the past (5).

COVID-19 has raised a global concern because of its high transmission potential (6). It is a zoonotic disease and its occurrence in medical staff treating COVID-19 patients points to human-to-human route of transmission (7). In Pakistan, 206512 confirmed cases of COVID-19 have been documented by June 29, 2020, and 4167 patients died fromthe disease (8).

During the current critical situation in the entire world, health care workers (HCWs) are on the frontline and are directly involved in the examination, diagnosis, treatment, and care of COVID-19 patients. Therefore, they are at risk of developing mental distress and other psychological symptoms. The rapidly increasing number of new suspected and confirmed cases, extreme work load, inadequate personal protective equipments (PPEs) and face masks, shortage of drugs and hand sanitizers (3), widespread media coverage, and feeling of lacking support may all give rise to the mental burden of these HCWs (9).

Previous studies on 2003 SARS outbreak (10) showed that those HCWs were afraid of contagion and infection of their family, relatives and friends, felt uncertainty and stigmatization, and reported undergoing high level of stress, depression and anxiety symptoms, which could have long-term psychological associations $(2,9)$. Similar concerns of mental and psychological health are now arising in general public due to above given reasons (3) and the lockdown situation in the country. Cases of suicide in Bangladesh and India were reported recently, which could be associated with excessive fear or psychological distress due to COVID-19 (11).COVID-19 outbreak could have affected mental health of people; for instance, psychological distress, loneliness, fear, anger, anxiety, depression, panic attacks, and concern about the socioeconomic status. Because of social distancing and self-isolation, emotional health and social wellness had been challenged during the pandemic (12).

These worsening healthcare conditions in various countries need holistic comprehensive management for both physical as well as mental health. For instance,in response to COVID-19 pandemic, psychological assistance services, including internet-based counseling had been established by different mental health institutions in China (9).

Therefore, it is necessary to evaluate mental health outcomes among HCWs and the general public of Pakistan during COVID-19 pandemic by quantifying the symptoms of anxiety and depression, and exploring the potential risk factors with these symptoms. We hope our study findings will serve as an important evidence for the targeted interventions and promotion of psychological health among HCWs and general public.

\section{Methods}

\section{Study design and participants}

Due to the lockdown situation in Pakistan, we used a web-based cross sectional survey in English language to collect data in Pakistani population from March 27, 2020 to April 22, 2020. Data were collected through friend circle forwarding, WhatsApp sharing, and other social media platforms. This questionnaire was completely voluntary and participants could withdraw from the survey at any moment as per their choice. Electronic informed consent was obtained from each participant before starting the survey. Ethical committee approval was not required due to the lockdown during theCOVID-19 pandemic.

\section{Data collection}

All the participants reported their demographic data, knowledge about COVID-19, and 2standardized questionnaires, which assessed their depression and anxiety. The minimum age limit for answering the questionnaire was set at 15 years. We excluded all those who had serious mental illnesses or disorders affecting their mental health and those who refused to be investigated. Finally, 1014 participants who completed their questionnaires $(67.6 \%$ response rate) were included in the study.

\section{Demographic information}

Demographic information included gender, age, education, and occupation. Occupation included 3categories: (1) healthcare professionals, including doctors, nurses, physiotherapists, and health-related administrators; (2) undergraduate medical students, including students of all years of MBBS; and (3) the public, including teachers and students from schools, colleges and universities, lawyers, businessmen, and other relevant staff.

\section{COVID-19 awareness}

This section was divided into 2parts: (i) daily average time spent to focus on COVID-19 pandemic information; (ii) COVID-19-related knowledge, which included 12judgment questions: a. Accurate incubation period of SARS-CoV-2; b. Most common symptom of COVID-19; c. Spread via respiratory droplets; d. Current diagnostic test; e. A person who have contact with a patient of COVID-19 should be immediately isolated for 14 days; $\mathrm{f}$. Severe cases can cause pneumonia, kidney failure and death; g. Currently any medication to prevent or treat; $h$. Currently any vaccine present; i. Estimated mortality rate; j. COVID-19 affects only older people or not; k. Infection transmission in hot and humid environment; 1. Frequent handwashing as best protective measure; $\mathrm{m}$. Need to wear medical mask if not taking care of suspected case of COVID-19. Of all the above 13 questions, multiple options were given and one was considered as correct, so one point was given for correct answer and no points were given for uncertain or incorrect answers. Cutoff values for awareness scale were as follow: score $\leq 6$ points $(<50 \%)$, $7-10$ points $(50-<80 \%)$ and $11-13$ points $(\geq 80 \%)$ were considered to be 'not aware', 'aware' and 'well aware', respectively. It means that participants who answered 6or less than 6 correct answers ( $\leq 6$ points) were considered 
'not aware' while seven or more than seven correct answers ( $\geq 7$ points) were considered as 'aware'.

\section{Depression and anxiety}

Zung self-rating anxiety scale (SAS) (13) and Zung selfrating depression scale (SDS) (14) were used to assess anxiety and depression symptoms, respectively. SAS and SDS have been used in previous studies $(2,15)$ and found to have good reliability (Cronbach's alpha $=0.800$ and 0.844 , respectively). Both SAS and SDS are 20-item Likert and norm-referenced scales using a 4-point scale ranging from 1 (a little of the time, or none) to 4 (all of the time, or most). These 20 -item scales tap physiological and psychological symptoms and are rated by the participants according to how they applied to them within the past week. The total score of SAS and SDS ranges from 20-80, with increasing scores indicating more severe anxiety or depression. SAS/SDS score of 50-59 points, 60-69 points, and 70 or more indicates mild, moderate, and severe anxiety/depression respectively (15).

\section{Statistical analysis}

We conducted descriptive analyses to describe the demographic profile and awareness related to COVID-19 in
Pakistani population. The prevalence of anxiety and depression stratified by gender, age, occupation, awareness, prior knowledge about COVID-19, and time spent on news were reported. Chi-square test was used to compare the differences between groups. Using univariate and multivariate logistic regression models, we explored potential influencing factors for anxiety and depression during COVID-19 pandemic. We obtained odds ratio (OR), adjusted odds ratio (AOR), and 95\% confidence interval (95\% CI) from above-mentioned logistic regression models. Data were analyzed using SPSS version 22.0 and a $\mathrm{p}<0.05$ was considered as significant.

\section{Results}

Of the 1014 respondents, 499 (49.2\%) were males and $515(50.8 \%)$ were females. The mean age of participants was $26.42 \pm 7.73$ years (mean $\pm \mathrm{SD}$ ). Among all respondents, $181(17.9 \%)$ participants were healthcare professionals, 329(32.4\%) had heard about the virus before this pandemic, 631(62.2\%) participants spent $<1$ hour to focus on COVID-19 information, 75(7.4\%) participants were not aware of COVID-19, 47(4.6\%) participants had anxiety symptoms, and $145(14.3 \%)$ had depressive symptoms (Table 1).

Table 1. Demographic profile and knowledge of the study sample $(\mathrm{N}=1014)$

\begin{tabular}{|c|c|}
\hline Variable & $\mathrm{N}(\%)$ \\
\hline Total & $1014(100.0 \%)$ \\
\hline \multicolumn{2}{|l|}{ Gender } \\
\hline Male & $499(49.2 \%)$ \\
\hline Female & $515(50.8 \%)$ \\
\hline \multicolumn{2}{|l|}{ Age } \\
\hline Mean \pm SD (Range) & $26.42 \pm 7.73(15-68$ Years $)$ \\
\hline$\leq 20$ Years & $154(15.2 \%)$ \\
\hline $21-30$ Years & $643(63.4 \%)$ \\
\hline $31-40$ Years & $156(15.4 \%)$ \\
\hline 41-50 Years & $43(4.2 \%)$ \\
\hline $51-60$ Years & $13(1.3 \%)$ \\
\hline$\geq 61$ Years & $5(0.5 \%)$ \\
\hline \multicolumn{2}{|l|}{ Occupation } \\
\hline Healthcare Professionals ${ }^{\mathrm{a}}$ & $181(17.9 \%)$ \\
\hline Undergraduate Medical Students ${ }^{\mathrm{b}}$ & $323(31.9 \%)$ \\
\hline General Public ${ }^{\mathrm{c}}$ & $510(50.3 \%)$ \\
\hline \multicolumn{2}{|l|}{ Prior Knowledge about Corona Virus } \\
\hline Yes & $329(32.4 \%)$ \\
\hline No & $685(67.6 \%)$ \\
\hline \multicolumn{2}{|l|}{ Daily Time Spent to Focus on COVID-19 Information } \\
\hline$<1$ hour & $631(62.2 \%)$ \\
\hline 1-3 hours & $251(24.8 \%)$ \\
\hline$\geq 3$ hours & $132(13.0 \%)$ \\
\hline \multicolumn{2}{|l|}{ Awareness/Knowledge of COVID-19 score } \\
\hline Mean \pm SD (Range) & $9.70 \pm 2.00(0-13$ score $)$ \\
\hline Not aware (score $\leq 6$ points, $<50 \%$ ) & $75(7.4 \%)$ \\
\hline Aware (score $7-10$ points, $50 \%-<80 \%$ ) & $533(52.6 \%)$ \\
\hline Well aware (score $11-13$ points, $\geq 80 \%$ ) & $406(40.0 \%)$ \\
\hline \multicolumn{2}{|l|}{ Anxiety Symptoms (SAS Score) } \\
\hline Mean \pm SD (Range) & $32.86 \pm 8.13$ (20-68 score $)$ \\
\hline No Anxiety (SAS 20-49) & $967(95.4 \%)$ \\
\hline Mild Anxiety (SAS 50-59) & $38(3.7 \%)$ \\
\hline Moderate Anxiety (SAS 60-69) & $9(0.9 \%)$ \\
\hline \multicolumn{2}{|l|}{ Depression Symptoms (SDS Score) } \\
\hline Mean \pm SD (Range) & $37.45 \pm 10.07$ (20-75 score) \\
\hline No Depression (SDS 20-49) & $869(85.7 \%)$ \\
\hline Mild Depression (SDS 50-59) & $127(12.5 \%)$ \\
\hline Moderate Depression (SDS 60-69) & $16(1.6 \%)$ \\
\hline Severe Depression (SDS 70-80) & $2(0.2 \%)$ \\
\hline
\end{tabular}

Key: SD, Standard deviation; COVID-19, 2019 Corona Virus Disease; SAS, Self-rating Anxiety Scale; SDS, Self-rating Depression Scale; N, number (N=1014 for all \%)

${ }^{a}$ Included doctors, nurses, physiotherapists, and health-related administrators.

${ }^{\mathrm{b}}$ Included students of all years of MBBS.

${ }^{\mathrm{c}}$ Included teachers and students from schools, colleges and universities, lawyers, businessmen, and other relevant staff. 
Awareness of COVID-19 pandemic in Pakistani population stratified by gender, age, occupation, prior knowledge and time spent on news is shown in Table 2. The results showed statistically significant differences. Most of the participants who were aware (7-10 points) aged between 20-30 years. Most of the healthcare workers (115 of 1014) were well aware (11-13 points), while 63 out of 1014 par- ticipants in the general public were not aware ( $\leq 6$ points) of COVID-19.

Table 3 shows that anxiety was more prevalent in females (32 out of 1014) than in males (15 out of 1014), which was statistically significant $(p<0.05)$. When anxiety was compared with age groups, it showed that anxiety was absent in all participants aged above 50 years $(p>0.05$; ie,

Table 2.Awareness of COVID-19 pandemic in Pakistani population stratified by gender, age, occupation, prior knowledge, and daily time spent on news $(\mathrm{N}=1014)$

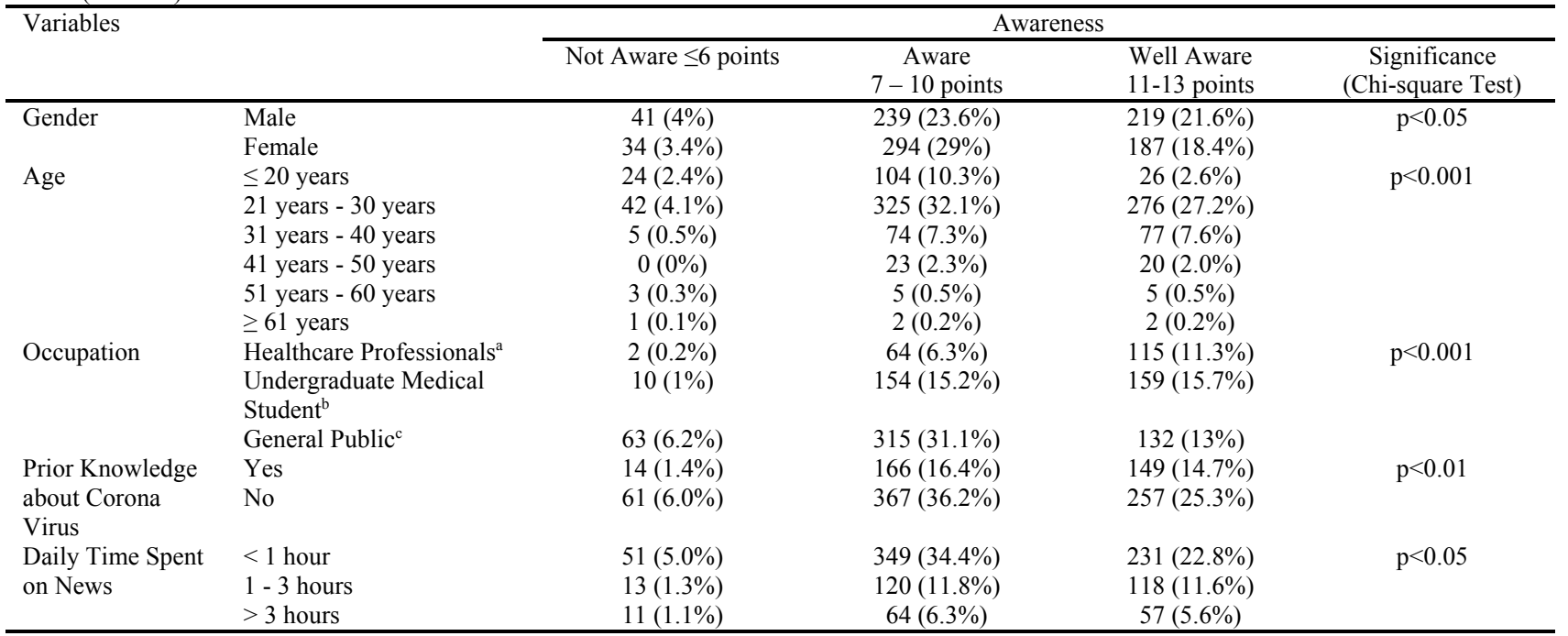

Key: $\mathrm{N}$, number $(\mathrm{N}=1014$ for all $\%)$.
${ }^{a}$ Included doctors, nurses, physiotherapists, and health-related administrators.

${ }^{\mathrm{b}}$ Included students of all years of MBBS.

c Included teachers and students from schools, colleges and universities, lawyers, businessmen, and other relevant staff.

Table 3. Prevalence of anxiety in Pakistani population stratified by gender, age, occupation, awareness level, prior knowledge, and time spent on news $(\mathrm{N}=1014)$

\begin{tabular}{|c|c|c|c|c|c|c|}
\hline \multirow[b]{2}{*}{ Variables } & & \multicolumn{5}{|c|}{ Anxiety Symptoms } \\
\hline & & $\begin{array}{l}\text { No Anxiety } \\
\text { (SAS 20-49) }\end{array}$ & $\begin{array}{l}\text { Mild Anxiety } \\
\text { (SAS 50-59) }\end{array}$ & $\begin{array}{l}\text { Moderate Anxiety } \\
\text { (SAS 60-69) }\end{array}$ & $\begin{array}{l}\text { Severe Anxiety } \\
\text { (SAS 70-80) }\end{array}$ & $\begin{array}{c}\text { Significance } \\
\text { (Chi-square Test) }\end{array}$ \\
\hline \multirow[t]{2}{*}{ Gender } & Male & $484(47.7 \%)$ & $14(1.4 \%)$ & $1(0.1 \%)$ & & $\mathrm{p}<0.05$ \\
\hline & Female & $483(47.6 \%)$ & $24(2.4 \%)$ & $8(0.8 \%)$ & & \\
\hline \multirow[t]{6}{*}{ Age } & $\leq 20$ years & $143(14.1 \%)$ & $8(0.8 \%)$ & $3(0.3 \%)$ & & $\mathrm{p}>0.05$ \\
\hline & 21 years -30 years & $613(60.5 \%)$ & $24(2.4 \%)$ & $6(0.6 \%)$ & & \\
\hline & 31 years -40 years & $151(14.9 \%)$ & $5(0.5 \%)$ & & & \\
\hline & 41 years -50 years & $42(4.1 \%)$ & $1(0.1 \%)$ & & & \\
\hline & 51 years -60 years & $13(1.3 \%)$ & & & & \\
\hline & $\geq 61$ years & $5(0.5 \%)$ & & & & \\
\hline \multirow[t]{3}{*}{ Occupation } & Healthcare Professionals ${ }^{\mathrm{a}}$ & $178(17.6 \%)$ & $3(0.3 \%)$ & & & $\mathrm{p}>0.05$ \\
\hline & $\begin{array}{l}\text { Undergraduate Medical } \\
\text { Student }^{\mathrm{b}}\end{array}$ & $309(30.5 \%)$ & $9(0.9 \%)$ & $5(0.5 \%)$ & & \\
\hline & Public ${ }^{c}$ & $480(47.3 \%)$ & $26(2.6 \%)$ & $4(0.4 \%)$ & & \\
\hline \multirow[t]{3}{*}{ Awareness } & Not Aware ${ }^{\mathrm{d}}$ & $63(6.2 \%)$ & $9(0.9 \%)$ & $3(0.3 \%)$ & & $\mathrm{p}<0.001$ \\
\hline & Aware $^{\mathrm{e}}$ & $511(50.4 \%)$ & $19(1.9 \%)$ & $3(0.3 \%)$ & & \\
\hline & Well Aware ${ }^{f}$ & $393(38.8 \%)$ & $10(1.0 \%)$ & $3(0.3 \%)$ & & \\
\hline \multirow{5}{*}{$\begin{array}{l}\text { Prior Knowledge } \\
\text { about corona virus } \\
\text { Daily Time Spent } \\
\text { on News }\end{array}$} & Yes & $316(31.2 \%)$ & $11(1.1 \%)$ & $2(0.2 \%)$ & & $\mathrm{p}>0.05$ \\
\hline & No & $651(64.2 \%)$ & $27(2.7 \%)$ & $7(0.7 \%)$ & & \\
\hline & $<1$ hour & $606(59.8 \%)$ & $23(2.3 \%)$ & $2(0.2 \%)$ & & $\mathrm{p}<0.01$ \\
\hline & $1-3$ hours & $242(23.9 \%)$ & $5(0.5 \%)$ & $4(0.4 \%)$ & & \\
\hline & $>3$ hours & $119(11.7 \%)$ & $10(1.0 \%)$ & $3(0.3 \%)$ & & \\
\hline
\end{tabular}

Key: SAS, Self-rating Anxiety Scale; N, number ( $\mathrm{N}=1014$ for all \%).

${ }^{a}$ Included doctors, nurses, physiotherapists, and health-related administrators.

${ }^{\mathrm{b}}$ Included students of all years of MBBS.

${ }^{\mathrm{c}}$ Included teachers and students from schools, colleges and universities, lawyers, businessmen, and other relevant staff.

${ }^{\mathrm{d}} \mathrm{scores} \leq 6$ points.

${ }^{\mathrm{e}}$ scores $7-10$ points.

${ }_{\text {f }}$ cores 11-13 points. 
not statistically significant). Anxiety was less prevalent in healthcare professionals as compared to medical students and general public, but this result was not statistically significant ( $p>0.05)$. Table 4 shows that depression was more prevalent in females (95 out of 1014) than in males (50 out of 1014), which was statistically significant $(\mathrm{p}<0.05)$. Similar to results for anxiety, depression was also absent in participants aged above 50 years $(\mathrm{p}<0.05)$.

The associations of potential influence factors with anxiety and depression were present in this study as shown in Table 5. In univariate and multivariate logistic regression models, gender (i.e, female) was significantly associated with anxiety $(0 \mathrm{R}=2.13,95 \% \mathrm{CI}=1.14-4.00 ; \mathrm{AOR}=2.13$, $95 \% \mathrm{CI}=1.14-4.00)$ and depression $(\mathrm{OR}=$ $2.03,95 \% \mathrm{CI}=1.40-2.93 ; \mathrm{AOR}=2.03,95 \% \mathrm{CI}=1.40-2.93)$ in Pakistani population. Age ( $\leq 30$ years) was significantly associated with depression $(\mathrm{OR}=2.25,95 \% \mathrm{CI}=1.32-3.82$; $\mathrm{AOR}=2.25,95 \% \mathrm{CI}=1.32-3.82)$. Occupation was also significantly associated with anxiety (general public, $\mathrm{OR}=5.92,95 \% \mathrm{CI}=3.22-10.89 ; \mathrm{AOR}=5.92,95 \% \mathrm{CI}=3.22-$ 10.89) and depression (medical students, $\mathrm{OR}=2.23$, $95 \% \mathrm{CI}=1.55-3.20 ; \mathrm{AOR}=2.23,95 \% \mathrm{CI}=1.55-3.20)$. Time spent on the news or getting COVID-19 information $(>3$ hours) was significantly associated with anxiety

Table 4.Prevalence of depression in Pakistani population stratified by gender, age, occupation, awareness level, prior knowledge, and time spent on news $(\mathrm{N}=1014)$

\begin{tabular}{|c|c|c|c|c|c|c|}
\hline \multirow{2}{*}{\multicolumn{2}{|c|}{ Variables }} & \multicolumn{5}{|c|}{ Depression Symptoms } \\
\hline & & $\begin{array}{c}\text { No } \\
\text { Depression } \\
\text { (SDS 20-49) }\end{array}$ & $\begin{array}{c}\text { Mild } \\
\text { Depression } \\
\text { (SDS 50-59) }\end{array}$ & \multirow{2}{*}{$\begin{array}{c}\begin{array}{c}\text { Moderate } \\
\text { Depression } \\
\text { (SDS 60-69) }\end{array} \\
3(0.3 \%)\end{array}$} & $\begin{array}{c}\text { Severe } \\
\text { Depression } \\
(\text { SDS 70-80) } \\
\end{array}$ & $\begin{array}{c}\text { Significance } \\
\text { (Chi-square Test) }\end{array}$ \\
\hline \multirow{2}{*}{ Gender } & Male & $449(44.3 \%)$ & $47(4.6 \%)$ & & & $\mathrm{n}<0001$ \\
\hline & Female & $420(41.4 \%)$ & $80(7.9 \%)$ & $13(1.3 \%)$ & $2(0.2 \%)$ & $P=0.001$ \\
\hline \multirow[t]{6}{*}{ Age } & $\leq 20$ years & $121(11.9 \%)$ & $28(2.8 \%)$ & $3(0.3 \%)$ & $2(0.2 \%)$ & $\mathrm{p}<0.05$ \\
\hline & 21 years - 30 years & $548(54.0 \%)$ & $84(8.3 \%)$ & $11(1.1 \%)$ & & \\
\hline & 31 years - 40 years & $142(14.0 \%)$ & $12(1.2 \%)$ & $2(0.2 \%)$ & & \\
\hline & 41 years - 50 years & $40(3.9 \%)$ & $3(0.3 \%)$ & & & \\
\hline & 51 years -60 years & $13(1.3 \%)$ & & & & \\
\hline & $\geq 61$ years & $5(0.5 \%)$ & & & & \\
\hline \multirow[t]{3}{*}{ Occupation } & Healthcare Professionals ${ }^{\mathrm{a}}$ & $162(16.0 \%)$ & $18(1.8 \%)$ & $1(0.1 \%)$ & & $\mathrm{p}>0.05$ \\
\hline & Medical Student ${ }^{\mathrm{b}}$ & $266(26.2 \%)$ & $49(4.8 \%)$ & $7(0.7 \%)$ & $1(0.1 \%)$ & \\
\hline & Public ${ }^{c}$ & $441(43.5 \%)$ & $60(5.9 \%)$ & $8(0.8 \%)$ & $1(0.1 \%)$ & \\
\hline \multirow[t]{3}{*}{ Awareness } & Not Aware ${ }^{d}$ & $56(5.5 \%)$ & $16(1.6 \%)$ & $3(0.3 \%)$ & & $\mathrm{p}>0.05$ \\
\hline & Aware & $459(45.3 \%)$ & $67(6.6 \%)$ & $6(0.6 \%)$ & $1(0.1 \%)$ & \\
\hline & Well Aware ${ }^{f}$ & $354(34.9 \%)$ & $44(4.3 \%)$ & $7(0.7 \%)$ & $1(0.1 \%)$ & \\
\hline \multirow{5}{*}{$\begin{array}{l}\text { Prior Knowledge } \\
\text { about corona virus } \\
\text { Daily Time Spent } \\
\text { on News }\end{array}$} & Yes & $275(27.1 \%)$ & $49(4.8 \%)$ & $5(0.5 \%)$ & & $\mathrm{p}>0.05$ \\
\hline & No & $594(58.6 \%)$ & $78(7.7 \%)$ & $11(1.1 \%)$ & $2(0.2 \%)$ & \\
\hline & $<1$ hour & $540(53.3 \%)$ & $82(8.1 \%)$ & $8(0.8 \%)$ & $1(0.1 \%)$ & $\mathrm{p}>0.05$ \\
\hline & $1-3$ hours & $215(21.2 \%)$ & $31(3.1 \%)$ & $4(0.4 \%)$ & $1(0.1 \%)$ & \\
\hline & $>3$ hours & $114(11.2 \%)$ & $14(1.4 \%)$ & $4(0.4 \%)$ & & \\
\hline
\end{tabular}

Key: SDS, Self-rating Depression Scale; $\mathrm{N}$, number ( $\mathrm{N}=1014$ for all \%).

${ }^{\text {a }}$ Included doctors, nurses, physiotherapists, and health-related administrators.

${ }^{\mathrm{b}}$ Included students of all years of MBBS.

${ }^{\mathrm{c}}$ Included teachers and students from schools, colleges and universities, lawyers, businessmen, and other relevant staff.

${ }^{\mathrm{d}}$ scores $\leq 6$ points.

escores $7-10$ points.

scores $11-13$ points.

Table 5. Results of univariate and multivariate logistic regression analyses $(\mathrm{N}=1014)$

\begin{tabular}{|c|c|c|c|c|c|}
\hline \multirow[t]{2}{*}{ Variables } & & \multicolumn{2}{|c|}{ Anxiety Symptoms } & \multicolumn{2}{|c|}{ Depression Symptoms } \\
\hline & & OR(95\%CI) & $\operatorname{AOR}(95 \% \mathrm{CI})$ & $\mathrm{OR}(95 \% \mathrm{CI})$ & $\operatorname{AOR}(95 \% \mathrm{CI})$ \\
\hline \multirow[t]{2}{*}{ Gender } & Male & 1.00 & 1.00 & 1.00 & 1.00 \\
\hline & Female & $2.13(1.14-4.00)^{*}$ & $2.13(1.14-3.99)^{*}$ & $2.03(1.40-2.93) *$ & $2.03(1.40-2.93) *$ \\
\hline \multirow[t]{2}{*}{ Age } & $\leq 30$ year & $1.90(0.79-4.55)$ & $1.90(0.79-4.55)$ & $2.25(1.32-3.82)^{*}$ & $2.25(1.32-3.82)^{*}$ \\
\hline & $>30$ year & 1.00 & 1.00 & 1.00 & 1.00 \\
\hline \multirow[t]{3}{*}{ Occupation } & HealthCare Professional $^{\mathrm{a}}$ & 1.00 & 1.00 & 1.00 & 1.00 \\
\hline & Medical Students ${ }^{\mathrm{b}}$ & $2.99(1.57-5.67)$ & $2.99(1.57-5.67)$ & $2.23(1.55-3.20)^{*}$ & $2.23(1.55-3.20)^{*}$ \\
\hline & General Public ${ }^{\mathrm{c}}$ & $5.92(3.22-10.89)^{*}$ & $5.92(3.22-10.89)^{*}$ & $1.33(0.94-1.90)$ & $1.33(0.94-1.90)$ \\
\hline Prior Knowledge & Yes & 1.00 & 1.00 & $1.28(0.88-1.84)$ & $1.28(0.88-1.84)$ \\
\hline about corona virus & No & $1.26(0.66-2.43)$ & $1.27(0.66-2.43)$ & 1.00 & 1.00 \\
\hline Daily Time Spent on & $<1$ hour & 1.00 & 1.00 & $1.09(0.76-1.57)$ & $1.09(0.76-1.57)$ \\
\hline \multirow[t]{2}{*}{ News } & $1-3$ hours & $1.04(0.49-2.19)$ & $1.04(0.49-2.19)$ & $1.07(0.71-1.60)$ & $1.07(0.71-1.60)$ \\
\hline & $>3$ hours & $4.02(2.06-7.84) *$ & $4.02(2.06-7.84) *$ & 1.00 & 1.00 \\
\hline Awareness/ & Not Aware ${ }^{\mathrm{d}}$ & $4.92(2.43-9.90) *$ & $4.92(2.43-9.94) *$ & $2.18(1.25-3.80)^{*}$ & $2.18(1.25-3.80)^{*}$ \\
\hline Knowledge & Aware & 1.00 & 1.00 & 1.00 & 1.00 \\
\hline \multicolumn{6}{|c|}{$\begin{array}{l}\text { Key: OR, odds ratio; AOR, adjusted odds ratio; } 95 \% \mathrm{CI}, 95 \% \text { confidence interval; N, number. } \\
\text { a Included doctors, nurses, physiotherapists, and health-related administrators. } \\
\text { b Included students of all years of MBBS. } \\
{ }^{\mathrm{c}} \text { Included teachers and students from schools, colleges and universities, lawyers, businessmen, and other relevant staff. } \\
{ }^{\mathrm{d}} \mathrm{s} \text {. } \\
\text { eres } \leq 6 \text { points. } \\
\text { escores } \geq 7 \text { points. } \\
\text { "p }<0.05 \text {. }\end{array}$} \\
\hline
\end{tabular}


$(\mathrm{OR}=4.02,95 \% \mathrm{CI}=2.06-7.84 ; \mathrm{AOR}=4.02,95 \% \mathrm{CI}=2.06-$ 7.84). Awareness level (not aware) was also significantly associated with both anxiety $(\mathrm{OR}=4.92,95 \% \mathrm{CI}=2.43$ 9.90; $\quad \mathrm{AOR}=4.92, \quad 95 \% \mathrm{CI}=2.43-9.94)$ and depression $(\mathrm{OR}=2.18,95 \% \mathrm{CI}=1.25-3.80 ; \mathrm{AOR}=2.18,95 \% \mathrm{CI}=1.25$ $3.80)$.

\section{Discussion}

In our study sample of 1014 , most of the respondents (92.6\%) were aware of COVID-19, and this result was similar to other studies that reported $94.5 \%$ (3) andup to $90 \%$ (16) awareness. High level of awareness was expected due to overwhelming news reports related to COVID-19 pandemic, public health emergency in the entire world, and increased use of various channels of information including internet.

In our study, overall prevalence of anxiety and depression symptoms was $4.6 \%$ and $14.3 \%$, respectively. In contrast, Huang Y and Zhao N (3) reported 34\% and 18.1\%, while Wang $C$ et al( 17 ) reported $36.4 \%$ and $30.3 \%$ anxiety and depression symptoms, respectively, in Chinese population. Before COVID-19 pandemic, a study in 2016 had reported anxiety and depression ranging from $22 \%$ to $60 \%$ (18). The relatively less mental health outcomes reported in our study could be due to difference in the investigation tools, relatively less total number of confirmed cases and deaths in our country due to COVID-19, and difference in the targeted population. Another important reason could be that we collected data during the initial phase of the pandemic in Pakistan when people were not taking it seriously. In our study, possible reasons of presence of anxiety and depression symptoms could be due to the uncertainty of the epidemic progression, fear of being infected, and concerns about the health of self and other family members (9).Previous studies had also shown that public health problems occurred during Ebola(19) and SARS (20) outbreaks.

In our study 3 out of $181(1.7 \%)$ healthcare professionals had mild anxiety, while 19 out of $181(10.5 \%)$ had mild to moderate depression. In contrast, first line doctors in China had $11.4 \%$ and $45.6 \%$ anxiety and depression symptoms (2). The reason for this difference could be that China reported the highest number of cases and deaths in the initial phase of the pandemic and the doctors included in their study were only first-line doctors, while in our study healthcare professionals included medical doctors, nurses, pharmacists, and physiotherapists. Atif $\mathrm{k}$ et al in 2016 revealed $34 \%$ and $24.8 \%$ mild to moderate anxiety and depression in Pakistani doctors, respectively, while $7.2 \%$ and $1 \%$ had severe anxiety and depression, respectively (21).

Our study revealed that anxiety and depression are both more prevalent in participants younger than 40 years, and this result is similar to the study conducted by Huang Y and Zhao N (3). This could be due to more involvement of young people in the news channels, current updates, and increased use of social media.

After univariate and multivariate logistic regression analyses, we found few potential risk factors for anxiety and depression in our population. In this study we found that male gender was a protective factor for anxiety and depression in our population. Zhu J et al (2), and Lai J et al (9) concluded similar results in their studies. Before COVID-19 pandemic, the same association was observed by Ahmed et al in Pakistani population (21).Pubertal hormonal changes lead to greater limbic system hyper activation in females, conferring greater responsivity to negative emotional stimuli, and leading to potential risk factors of specific anxiety and depression states (22). Men may be less likely to develop depression than women, but this does not mean that men having depression are not distressed and impaired (23).

In the present study we found medical students were significantly associated with depression. Similarly, mental health of medical students in China was significantly affected, and they reported to have anxiety symptoms, and their results indicated that students living in urban areas, stability of student's family income, and living with parents were the protective factors against anxiety. Students can have mental health issues due to the effect of COVID19 on their routine studies (24). Xiao C reported that in the absence of interpersonal communication, it was more likely that anxiety and depression would occur and worsen (25). A multicenter study conducted in 2014 also reported anxiety and depression symptoms in Pakistani medical students up to $45 \%$ (26). We also found in our study that the general public had anxiety as reported by Wang $\mathrm{C}$ et al (17). This could be due to less awareness and knowledge of the general public about COVID-19 and due to impact of flying rumors in the public.

In our study we found average daily time ( $\geq 3$ hours) spent on news and updating knowledge related to COVID19 was significantly associated with development of anxiety symptoms. This result was similar to the studies conducted by Su TP et al (27) during SARS outbreak and Huang $\mathrm{Y}$ et al(3) during the initial phase of COVID-19 pandemic. Furthermore, the overwhelming and sensational news headlines on electronic media and erroneous news reports have added to anxiety in people (28). The manifestation of this panic mood may be linked to the body's normal protective response to the stress caused by the outbreak (10). As the number of cases and deaths increased every day, people became more hopeless, and felt helplessness, which caused more mental health problems (29).

In our study we found that participants who were not aware ( $\leq 6$ points) were more likely to become anxious and depressive. If people do not know the facts about COVID19 , they will have more mental health issues. Anyone who knew the signs and symptoms, diagnostic tests, prevention, and estimated mortality rates of COVID-19, would be less likely to become anxious and depressive. Thus, we can say that accurate knowledge is a protective factor for anxiety and depression. During COVID-19 pandemic, information is flowing at high speed, often through unfiltered channels, in the entire world. Much of this information is speculative; that is, derived from inconclusive and preliminary studies, creating confusion and anxiety among people (30).

This research has several limitations. First, the assess- 
ment was performed by general mental health tools, not scales designed to assess mental health related to COVID19 outbreak specifically. Second, because it was a cross sectional survey, we were unable to establish causal inferences. Third, we were unable to distinguish between new and preexisting mental health symptoms in our population due to rapid web-based assessment during the pandemic. Fourth, there is a possibility of selection bias because of voluntary sampling through online system using different social media platforms. Finally, although our sample size was not small, participation of few elder people in the survey might have affected the final results.

After this study few interventions are proposed as follow: First, special attention should be warranted regarding mental health wellbeing of young people and women during the pandemic. Second, exercising regularly and taking adequate rest after doing a routine work are recommended. Third, limiting the time of receiving information related to COVID-19, focusing on facts only, and preventing the spread of rumors and fake news about the pandemic are suggested.

\section{Conclusion}

In conclusion, we identified potential factors associated with mental health problems during the pandemic in our population. Although we did not find a major mental health burden in our study, there is a dire need to pay more attention towards the mental health among vulnerable groups like medical students, young people, and especially women. People who were less aware and spent more time on news to get information about COVID-19 were at a high risk of developing anxiety and depression. Targeted psychological interventions are required to improve mental health. As young people are more attracted to mobile applications, psychological interventions like CBT (cognitive behavioral therapy) should preferably be delivered online or through smart-phones to reduce the risk of spread of the virus. We found that awareness and accurate knowledge about COVID-19 was associated with lower levels of anxiety and depression, so more awareness campaigns and reduction of spread of rumors could further improve the mental health of people.

\section{Acknowledgement}

We are thankful to all the participants who helped in data collection in the study.

\section{Conflict of Interests}

The authors declare that they have no competing interests.

\section{References}

1. Zhao D, Yao F, Wang L, Zheng L, Gao Y, Ye J, et al. A comparative study on the clinical features of COVID-19 pneumonia to other pneumonias. Clin Infect Dis. 2020 Mar 12.

2. Zhu J, Sun L, Zhang L, Wang H, Fan A, Yang B,et al. Prevalence and Influencing Factors of Anxiety and Depression Symptoms in the First-Line Medical Staff Fighting Against COVID-19 in Gansu. Front Psychiatry. 2020;11.

3. Huang Y, Zhao N. Generalized anxiety disorder, depressive symptoms and sleep quality during COVID-19 outbreak in China: a web- based cross-sectional survey. Psychiatry Res. 2020 Apr 12:112954.

4. Coronavirus disease (COVID-19) outbreak [Internet]. World Health Organization; [cited 2020 Feb 17]. Available from https:/www.who.int/emergencies/diseases/ novelcoronavirus-2019

5. Mukhtar F, Mukhtar N. Coronavirus (COVID-19): Let's Prevent Not Panic. J Ayub Med Coll Abbottabad. 2020 Feb 21;32(1):141-4.

6. Chen N, Zhou M, Dong X, Qu J, Gong F, Han Y,et al. Epidemiological and clinical characteristics of 99 cases of 2019 novel coronavirus pneumonia in Wuhan, China: a descriptive study. Lancet. 2020Feb15;395(10223):507-13.

7. Wang C, Horby PW, Hayden FG, Gao GF. A novel coronavirus outbreak of global health concern. Lancet. 2020Feb15;395(10223):4703 .

8. World Health Organization, 2020. Coronavirus Disease (COVID19): Situation report-161.[Cited June 30, 2020.]https://www.who.int/ emergencies/diseases/novel-coronavirus-2019/situation-reports

9. Lai J, Ma S, Wang Y, Cai Z, Hu J, Wei N, et al. Factors Associated With Mental Health Outcomes Among Health Care Workers Exposed to Coronavirus Disease 2019. JAMA Netw Open. 2020 Mar2;3(3):e203976-e203976.

10. Maunder R, Hunter J, Vincent L, Bennett J, Peladeau N, Leszcz M, et al. The immediate psychological and occupational impact of the 2003 SARS outbreak in a teaching hospital.CMAJ. 2003May13;168(10):1245-51.

11. Alyami M, Henning M, Krägeloh CU, Alyami H. Psychometric evaluation of the Arabic version of the Fear of COVID-19 Scale. Int J Ment Health Addict. 2020May16:1.

12. Mukhtar S. Mental health and psychosocial aspects of coronavirus outbreak in Pakistan: psychological intervention for public mental health crisis. Asian J Psychiatr. 2020.

13. Zung WW. A rating instrument for anxiety disorders. Psychosomatics. 1971 Nov.

14. Zung WW. A self-rating depression scale. Arch Gen Psychiatry. 1965Jan1;12(1):63-70.

15. Guo J, Liao L, Wang B, Li X, Guo L, Tong Z, et al. Psychological Effects of COVID-19 on Hospital Staff: A National Cross-Sectional Survey of China Mainland. Available at SSRN 3550050. 2020 Mar 2.

16. Hussain T, Khan S, Gilani US, Raza SMM. Evaluation of General Awareness among Professionals Regarding COVID-19: A Survey Based Study from Pakistan. Res Sq. 2020.

17. Wang C, Pan R, Wan X, Tan Y, Xu L, Ho CS, et al. Immediate psychological responses and associated factors during the initial stage of the 2019 coronavirus disease (COVID-19) epidemic among the general population in china. Int J Environ Res Public Health. 2020 Jan;17(5):1729.

18. Ahmed B, Enam SF, Iqbal Z, Murtaza G, Bashir S. Depression and anxiety: a snapshot of the situation in Pakistan. Int J Neurosci Behav Sci. 2016;4(2):32.)

19. Shultz JM, Baingana F, Neria Y. The 2014 Ebola outbreak and mental health: current status and recommended response. JAMA. 2015Feb10;313(6):567-8

20. Mak IW, Chu CM, Pan PC, Yiu MG, Chan VL. Long-term psychiatric morbidities among SARS survivors. Gen Hosp Psychiatry. 2009 Jul 1;31(4):31826

21. Atif K, Khan HU, Ullah MZ, Shah FS, Latif A. Prevalence of anxiety and depression among doctors; the unscreened and undiagnosed clientele in Lahore, Pakistan. Pak J Med Sci. 2016 Mar;32(2):294.)

22. Parker G, Brotchie H. Gender differences in depression. Int Rev Psychiatry. 2010Oct1;22(5):429-36.

23. Salk RH, Hyde JS, Abramson LY. Gender differences in depression in representative national samples: meta-analyses of diagnoses and symptoms. Psychol Bull. 2017Aug;143(8):783.

24. Cao W, Fang Z, Hou G, Han M, Xu X, Dong J, et al. The psychological impact of the COVID-19 epidemic on college students in China. Psychiatry Res. 2020 Mar 20:112934.

25. Xiao C. A novel approach of consultation on 2019 novel coronavirus (COVID-19)-related psychological and mental problems: structured letter therapy. Psychiatry Investig.2020Feb;17(2):175.

26. Hashmi AM, Aftab MA, Naqvi SH, Sajjad W, Mohsin M, Khawaja IS. Anxiety and depression in Pakistani medical students: a multicenter study. Health Med. 2014;8(7):813-20.

27. Su TP, Lien TC, Yang CY, Su YL, Wang JH, Tsai SL, et al. Prevalence of psychiatric morbidity and psychological adaptation of the nurses in a structured SARS caring unit during outbreak: A prospective and periodic assessment study in Taiwan. J Psychiatr Res. 
COVID-19 and mental health

2007Jan1;41(1-2):119-30.

28. Ayittey FK, Ayittey MK, Chiwero NB, Kamasah JS, Dzuvor C. Economic impacts of Wuhan 2019-nCoV on China and the world. J Med Virol. 2020May;92(5):473-5.

29. Shaw SC. Hopelessness, helplessness and resilience: The importance of safeguarding our trainees' mental wellbeing during the COVID-19 pandemic. Nurse Educ Pract. 2020Mar;44:102780.

30. Ruffell D. Coronavirus SARS-CoV-2: filtering fact from fiction in the infodemic: Q\&A with virologist Professor Urs Greber. FEBS Lett. 2020Apr;594(7):1127-31 